\title{
Interactive comment on "A comprehensive characterization of ice nucleation by three different types of cellulose particles immersed in water: lessons learned and future research directions" by Naruki Hiranuma et al.
}

Naruki Hiranuma et al.

nhiranuma@wtamu.edu

Received and published: 16 February 2019

Please see the attached Supplement.

Please also note the supplement to this comment:

https://www.atmos-chem-phys-discuss.net/acp-2018-933/acp-2018-933-AC2- 
2018.

ACPD

Interactive

comment

Printer-friendly version

Discussion paper 